\title{
Low concentration fluoride stimulates cell motility of epithelial cells in vitro
}

\author{
Yuki Arakawa ${ }^{1}$, Ujjal K. Bhawal ${ }^{2}$, Takeharu Ikoma ${ }^{2}$, Kazunari Kimoto ${ }^{1}$, Kazumi Kuroha ${ }^{1}$, Tomoka Kubota, \\ Nobushiro Hamada ${ }^{3}$, Eiro Kubota ${ }^{2}$ and Hirohisa AraKawA ${ }^{1}$ \\ ${ }^{1}$ Department of Health Science, Division of Oral Health; ${ }^{2}$ Department of Oral and Maxillofacial Surgery; and ${ }^{3}$ Department of Infection \\ Control, Division of Microbiology, Kanagawa Dental College, Kanagawa 238-8580, Japan
}

(Received 2 July 2009; and accepted 27 July 2009)

\begin{abstract}
Oral mucosal tissue can serve as a long-term fluoride reservoir following topical application and retain a small amount of fluoride in oral environment for prevention of dental caries. The aim of this study was to determine the effect of low level sodium fluoride $(\mathrm{NaF})$ on the proliferation and migration of epithelial cells in vitro. Human primary gingival epithelial cells and human epidermal HaCaT keratinocytes were used. Cultured epithelial cells, treated with various concentrations of NaF ranging from $5 \mu \mathrm{M}$ to $500 \mu \mathrm{M}$, were investigated by 3-(4,5-dimethylthiazol-2-yl)-5(3-carboxymethoxyphenyl)-2-(4-sulfophenyl)-2H-tetrazolium, inner salt (MTS) assay, wound healing assay, invasion assay and quantitative real-time PCR. MTS assay revealed that fluoride added to human gingival epithelial cells elevated cell proliferation at a concentration of $5 \mu \mathrm{M}$ or more. The wound healing assay and invasion assay confirmed this observation. Quantitative real-time PCR revealed that low concentration of NaF up-regulated fibronectin mRNA expression in fluoride-treated cells compared with controls. These results suggest that a low concentration of $\mathrm{NaF}$ is able to induce cell proliferation, migration, and matrix production in epithelial cells. Our results provide new information on epithelial cell adhesion and may thus aid in the understanding of periodontal physiology.
\end{abstract}

Several cell types have been identified within gingival connective tissue, and gingival fibroblasts, which account for most connective tissue cells, are likely to be responsible for the constant functional adaptation of gingival connective tissue (15). The structural composition of the epithelial-connective tissue interface is influenced by interactions between epithelial cells and fibroblasts. Although both tissues maintain a harmonious relationship under normal and diseased conditions, the characteristic differences between them remain largely unknown.

Fluoride has long been recognized as one of the best public health measures in the prevention of

Address correspondence to: Ujjal K. Bhawal, Department of Oral and Maxillofacial Surgery, Kanagawa Dental College, 82 Inaoka-cho, Yokosuka 238-8580, Japan

Tel: +81-468-22-9571, Fax: +81-468-22-9571

E-mail: bhawal@kdcnet.ac.jp dental caries (9). It also has a potential role in the prevention of osteoporosis (14). However, acute or chronic exposure to high fluoride concentration results in enamel (4) and skeletal fluorosis (1), renal toxicity (31), and epithelial lung cell toxicity (28). Fluoride is present in natural fresh water and a concentration of $1.6-1.8 \mathrm{ppm}$ in drinking water is the threshold for the risk of dental fluorosis in the population (29). Fluoride ingestion between the ages of 15 and 30 months may be the main cause for fluorosis of the esthetically important central incisors in humans $(6,7)$.

The concentration of fluoride that cells are exposed to appears to be a critical factor in determining any changes in behavior that may occur. Gibson and co-workers used organ culture to show that $2 \mathrm{mM}$ fluoride affected the Rho/ROCK signal transduction pathway, resulting in elevated F-actin in ameloblasts (22). Millimolar levels of fluoride were 
also found to induce endoplasmic reticulum stress, apoptosis, and caspase-mediated DNA fragmentation in enamel organ epithelial-derived cell line (LS8) (19). It was reported that the toxicity on a SmulowGlickman human gingival epithelial cell line was first observed at an exposure to $1 \mathrm{mM}$ sodium fluoride $(\mathrm{NaF})$ for $24 \mathrm{~h}(32)$. Although the sensitivity to fluoride differs with the kind of cell and donor's age, it is true that a fluoride more than $\mathrm{mM}$ level has the toxicity to human cells. These previous studies made us investigate the effect of $\mathrm{NaF}$ at concentrations ranging from $5 \mu \mathrm{M}$ to $500 \mu \mathrm{M}$ on human epithelial cells, focusing on cell proliferation and migration.

It is well known that epithelial cells act as biochemical and physical barriers for protecting mucosal integrity when faced with microorganisms and toxic products (25). The present study provides additional information that complements previous studies on the effect of fluoride on epithelial cells. In gingival wound healing, epithelial cells cover the wound space at the phase of re-epithelialization. During re-epithelialization, migrating keratinocytes express fibronectin containing Extra Domain A $\left(\mathrm{EDA}^{+}\right.$fibronectin) and laminin-5 (12). Fibronectin is a high-molecular weight extracellular matrix glycoprotein involved in not only the wound healing process, but also cell adhesion, growth, migration, and differentiation. Laminin is also one of the extracellular matrix proteins and the major non-collagenous component of the basal lamina.

There is little information on the molecular-based characteristics of the oral gingival epithelium, and no reports to date have described their profiles in relation to $\mathrm{NaF}$. Therefore, in an attempt to clarify the effect of fluoride on epithelial cells, we examined the behavior of human epithelial cells cultured in fluoridated medium. We monitored different parameters reflecting cellular physiology: proliferation, migration, invasion, and matrix production at the level of gene expression. We found that epithelial cells exposed to low concentration fluoride show increased cell proliferation, motility and adhere to fibronectin and laminin-5. These findings, in association with those of previous studies, imply that fluoride exposure to epithelial cells should be limited to the $\mu \mathrm{M}$ level.

\section{MATERIALS AND METHODS}

Preparation of cells. Human primary gingival epithelial cells were prepared from healthy gingival tissues from donors $(n=3)$ with their informed con- sent. Briefly, the gingiva was treated with $0.025 \%$ trypsin and $0.02 \%$ EDTA overnight at $4{ }^{\circ} \mathrm{C}$ and epithelial and fibroblast cells were isolated. The cell suspension was centrifuged at $120 \times g$ for $5 \mathrm{~min}$, and the pellet was suspended in medium for epithelial cells containing $0.4 \% \mathrm{~V} / \mathrm{V}$ bovine pituitary extract, $10 \mu \mathrm{g} / \mathrm{mL}$ insulin, $0.1 \mathrm{ng} / \mathrm{mL}$ hEGF, $0.5 \mu \mathrm{g} / \mathrm{mL}$ hydrocortisone, $50 \mu \mathrm{g} / \mathrm{mL}$ gentamicin and $50 \mathrm{ng} / \mathrm{mL}$ amphotericin B (HuMedia-KG2; KURABO, Tokyo, Japan) and human epidermal $\mathrm{HaCaT}$ keratinocytes (kindly provided by Prof. Yoshihiro Abiko, Health Sciences University of Hokkaido, Japan) in Dulbeco's modified eagles medium (DMEM) $/ 10 \%$ fetal bovine serum (FBS). The cells were seeded in $60-\mathrm{mm}$ plastic tissue culture plates and incubated in $5 \% \mathrm{CO}_{2} / 95 \%$ air at $37^{\circ} \mathrm{C}$. When the cells reached sub-confluence, they were harvested and sub-cultured.

Cell proliferation assay. Cultured cells were harvested from $80 \%$ confluent monolayer cultures by a brief trypsinization with $0.1 \%$ trypsin and $0.1 \%$ EDTA. The cells were seeded at a density of 5,000 cells (primary gingival epithelial cells), and 3,000 cells (HaCaT) per well of 96-well tissue culture plates and cultured for $24 \mathrm{~h}$ in the regular medium. The medium was replaced with serum-free medium for $24 \mathrm{~h}$ and then treated with medium supplemented with $\mathrm{NaF}$ at final concentrations of 5,50 , or $500 \mu \mathrm{M}(0.095 \mathrm{ppm}, 0.95 \mathrm{ppm}$, or $9.5 \mathrm{ppm}$ F). Cell proliferation was assessed by MTS assay at 24 and $48 \mathrm{~h}$ after treatment. Cell Titer $96^{\circledR}$ Aqueous One Solution Reagent (Promega, Madison, WI, USA) was added directly to each well, incubated for $2 \mathrm{~h}$ and the absorbance at $490 \mathrm{~nm}$ was measured using a microplate reader.

Wound healing assay. To evaluate cell motility with $\mathrm{NaF}$, a wound healing assay of epithelial cells was performed. Cultured cells were harvested from $80 \%$ confluent monolayer cultures by a brief trypsinization with $0.1 \%$ trypsin and $0.1 \%$ EDTA. The cells were seeded at a density of $2 \times 10^{5}$ of $3.5-\mathrm{cm}$ culture dishes. Cells were grown to confluency in regular medium for 2 days. The regular medium was then replaced with the serum-free medium. After $24 \mathrm{~h}$, an artificial wound was carefully created, using a pipette tip to scratch the confluent cell monolayer to make a cell-free area. The medium was removed, washed twice and the medium was replaced by medium supplemented with $\mathrm{NaF}$ at final concentrations of $0,5,50$, and $500 \mu \mathrm{M}$. Cells migrating into the scraped area were observed and photographs were taken after $24 \mathrm{~h}$. In each experi- 
ment, wound closure was measured at six marked sites per dish, by inverse light microscopy with a grid reticule in the eyepiece of the microscope. Wound closure was quantified as percentage of the starting distance of the wound edges. All experiments were repeated three times on separate days for each condition. Data are presented as the mean \pm standard deviation of three independent experiments, performed on separate days.

In vitro invasion assay. A modified Boyden chamber assay was performed to examine the in vitro invasion of NaF-treated cells. Cell culture inserts (pore size 8 micron) with a thin layer of matrigel basement membrane matrix (BD Biosciences, Bedford, MA, USA) were placed in the wells of 24-well tissue culture plates. Cells were suspended in $500 \mu \mathrm{L}$ of serum-free medium at a density of $2.5 \times 10^{4}$ per well and placed in the upper part of the chamber. The lower part of the chamber was filled with serum-free medium with NaF. After 12 or $24 \mathrm{~h}$ incubation at $37^{\circ} \mathrm{C}$, the filters were carefully removed from the inserts, and stained with hematoxylin for $2 \mathrm{~min}$. The stained cells were mounted on microscope slides and counted under magnification (randomly selected high-power fields). The counting was performed in five fields in each sample, and the mean values from three independent experiments were used.

Quantitative real-time PCR. In total, $1 \mathrm{mg}$ of total RNA extracted (RNeasy Mini Kit; Qiagen KK, Tokyo, Japan) from cells were reverse-transcribed using High-Capacity cDNA Archive Kit (Applied Biosystems, Foster City, CA, USA). One-hundredth aliquot of the cDNA was subjected to real-time RT-PCR using TaqMan Gene Expression Assays (Applied Biosystems) for fibronectin (Assay ID Hs00277509_m1) and laminin-5 $\gamma 2$ chain (Assay ID Hs00194333_m1), and pre-developed TaqMan Assay Reagents (Applied Biosystems) for $\beta$-actin served as an internal control. More than three independent measurements were averaged and relative gene expression levels were calculated as a ratio to $\beta$-actin expression of each cell.

Measurement of fluoride concentrations. Fluoride concentrations in cell culture supernatants after $24 \mathrm{~h}$ exposure were measured by the ion-selective electrode method (ORION Research, Inc., Beverly, MA, USA). TISAB II was used for total ionic strength adjustment buffer.
Statistical analyses. Statistical analysis was done by one-way ANOVA and Dunnett's Test. A $P$ value of less than $0.05\left(^{*}\right)$ was considered significant, 0.01 $(* *)$; highly significant.

\section{RESULTS}

\section{Cell Proliferation}

Exposure of epithelial cells ( $\mathrm{HaCaT}$ and primary gingival epithelial cells) to different concentrations of $\mathrm{NaF}$, for $48 \mathrm{~h}$, had a significant effect on cell proliferation $(P=0.0215$ for $\mathrm{HaCaT}$ and $P=0.004$ for primary gingival epithelial cells) (Fig. 1A and B). Lower concentrations of $\mathrm{NaF}$ promoted epithelial cell proliferation with the peak at $50 \mu \mathrm{M}$. The higher levels of $\mathrm{NaF}$ (higher than $500 \mu \mathrm{M}$ ) drastically reduced cell proliferation (Fig. 2).

\section{Wound Healing Assay}

$\mathrm{HaCaT}$ cells were used to study cell motility and migration using an in vitro wound healing assay. NaF-non-treated $\mathrm{HaCaT}$ cells showed delayed closure than $50 \mu \mathrm{M} \mathrm{NaF-treated} \mathrm{cells} \mathrm{(Fig.} \mathrm{3A).} \mathrm{At}$ $24 \mathrm{~h}, 50 \mu \mathrm{M}$ NaF-treated cells had significantly more motility and migrational movements $(63.3 \pm$ $5.7 \%)$ than the non-treated cells $(78.6 \pm 7.6 \% ; P=$ 0.0019) (Fig. 3B).

\section{In vitro Invasion assay}

To explore whether $\mathrm{NaF}$ enhanced epithelial cell invasion, $\mathrm{HaCaT}$ cells were examined in invasion assay. Twenty-four hours after treatment, the numbers of invading cells slightly increased with the addition of NaF. The number of $5 \mu \mathrm{M} \mathrm{NaF-treated} \mathrm{cells} \mathrm{in-}$ vading into the matrigel was significantly higher $(39.8 \pm 10.4$ cells per well) than that of non-treated cells (30.8 \pm 5.9 cells per well, $P=0.0381)$ (Fig. 3 C).

\section{Quantitative real-time PCR}

RNA purified from fluoride-treated cells or nontreated cells was subjected to real-time PCR assay. The difference between the fluoride-treated sample and the control was significant $(P<0.05, \mathrm{n}=3)$. Fibronectin mRNA expression was 2.64-fold upregulated in $50 \mu \mathrm{M}$ fluoride-exposed cells compared with the non-treated cells. Laminin-5 expression was increased in $500 \mu \mathrm{M}$ fluoride-treated cells (Fig. 4).

\section{Measurement of fluoride concentrations}

The rate of NaF concentrations in culture supernatants after $24 \mathrm{~h}$ fluoride exposure was reduced to $2.8 \%$ (for $5 \mu \mathrm{M}$ ), $6.2 \%$ (for $50 \mu \mathrm{M}$ ), and $7.8 \%$ (for $500 \mu \mathrm{M})$. 
A

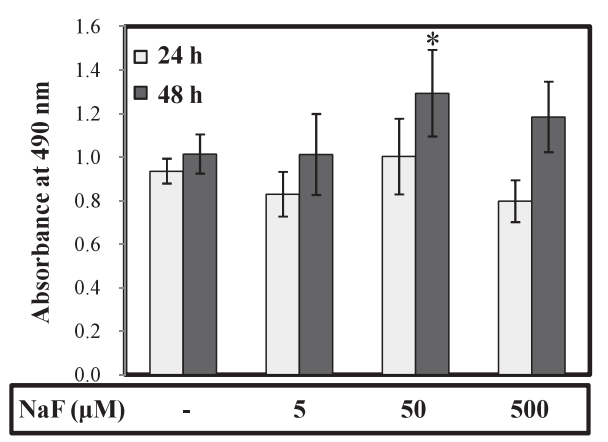

B

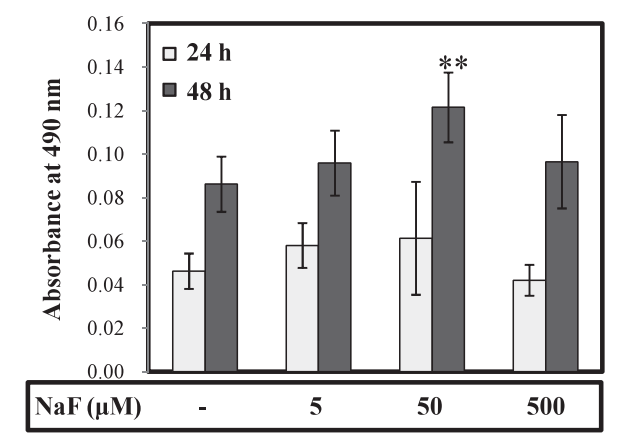

Fig. 1 Effect of NaF on epithelial proliferation. Cell growth was assessed by MTS assay at 24 and $48 \mathrm{~h}$ after NaF-treatment. Exposure of HaCaT (A) and human primary gingival epithelial cells (B) to $50 \mu \mathrm{M} \mathrm{NaF}$ for $48 \mathrm{~h}$ resulted in a significant increase in the number of living cells compared with non-treated cells $(P=0.0215$ and $P=0.004$, respectively).

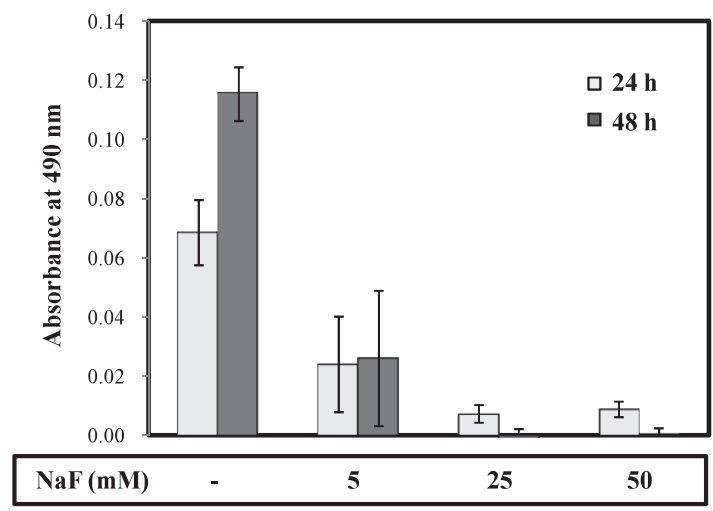

Fig. 2 Effect of high levels $(\mathrm{mM})$ of $\mathrm{NaF}$ on human primary gingival epithelial cell proliferation.

\section{DISCUSSION}

The major findings of this study were as follows: 1) lower concentrations of fluoride promoted the epithelial cell proliferation; and 2) there was significantly more motility and migrational movements with fluoride-treated cells and fibronectin and laminin-5 mRNA expression was increased in these cells.

Duckworth and Morgan have shown that oral mucosal tissue can serve as a long-term fluoride reservoir following topical application and, thereby, maintain a degree of protection against dental caries for a prolonged period (5). The effects of fluoride on cells (human gingival fibroblast, human epithelial lung cells) were highly concentration-dependent. We found that even a low level of fluoride had an effect on cell proliferation of human epithelial cells. The enhancement of cell proliferation at lower fluoride concentrations was similar to that reported in stud- ies of osteoblasts, where $\mu \mathrm{M}$ levels of fluoride were shown to increase cell proliferation through enhanced tyrosine kinase activity $(2,8)$. Thaweboon and co-workers reported a biphasic effect of fluoride at $\mathrm{mM}$ fluoride levels in dental pulp cells (27). Lower concentrations of fluoride promoted the proliferation of cells of the epithelial ameloblast-lineage, with the peak around $16 \mu \mathrm{M} \mathrm{NaF}$ (30). We found a statistically significant effect of fluoride on epithelial cells, as analyzed by proliferation assay, invasion assay or comparing extracellular matrix by real-time PCR. Our results show that fluoride added in cell-culture medium of human epithelial cells provoked specific modifications of cell proliferation at a concentration of $5 \mu \mathrm{M}$ or more. The $5 \mathrm{mM}$ fluoride level clearly reduced the cell growth (Fig. 2). Oguro et al. reported a growth inhibitory effect of fluoride on established cell lines at concentrations of about $20 \mathrm{ppm}$ (depending on cell strains), with a complete inhibition at $40-60 \mathrm{ppm}$ concentrations (24). Our observations are in agreement with these data, suggesting that the sensitivity of the human epithelial cells to fluoride is similar to that of other cell lines (e.g., HeLa cells, kidney fibroblasts, gingival fibroblasts) $(18,26)$. Our data showed that lower fluoride concentrations $(\mu \mathrm{M})$ stimulate cell growth and this was confirmed by flow cytometry analysis (our unpublished data). In addition, a low level of $\mathrm{NaF}$ did not show apoptotic characteristics in three primary gingival epithelial cells (our unpublished data).

We have established a model system to study the molecular effects of fluoride on the epithelium, using MTS assay, wound healing assay, invasion assay, and quantitative real-time PCR analysis. The hypothesis tested was that low level of $\mathrm{NaF}$ affects 
A

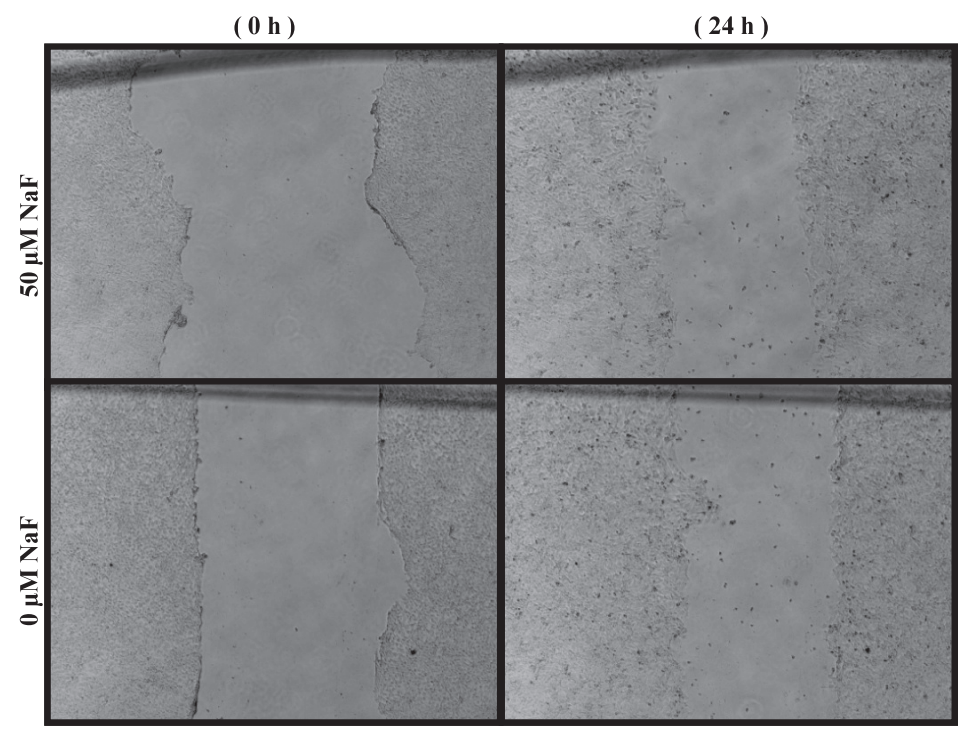

B
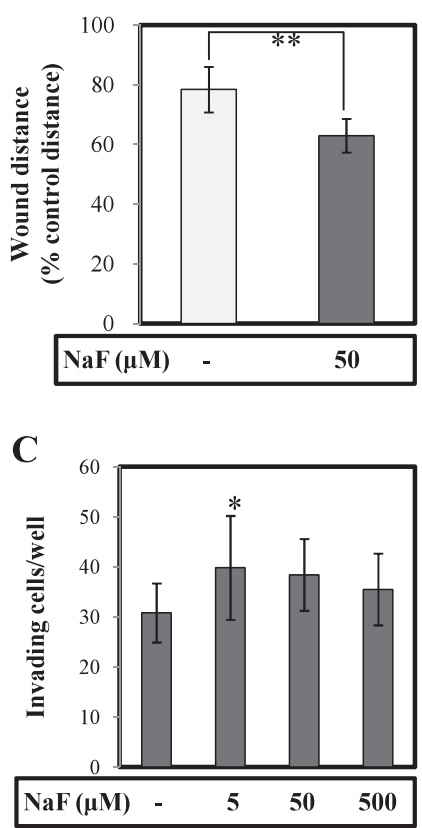

Fig. 3 Effect of $\mathrm{NaF}$ on wound healing and cell migration of epithelial cells. (A) Digital pictures of non-treated and $50 \mu \mathrm{M}$ $\mathrm{NaF}$-treated cells were taken at $\mathrm{O} \mathrm{h}$ as well as at $24 \mathrm{~h}$. (B) Wound closure was quantified as percentage of the starting distance of the wound edges. Data are presented as the mean \pm standard deviation of three independent experiments. The increase in wound healing seen in $50 \mu \mathrm{M} \mathrm{NaF}$-treated cells $(63.3 \pm 5.7 \%)$ in comparison with non-treated cells $(78.6 \pm 7.6 \%)$ was statistically significant $(P=0.0019)$. (C) In invasion assay, numbers of invading cells, which were able to degrade matrigel $24 \mathrm{~h}$ after treatment, significantly increased with the addition of $5 \mu \mathrm{M} \mathrm{NaF-treated} \mathrm{cells}(P=0.0381)$.

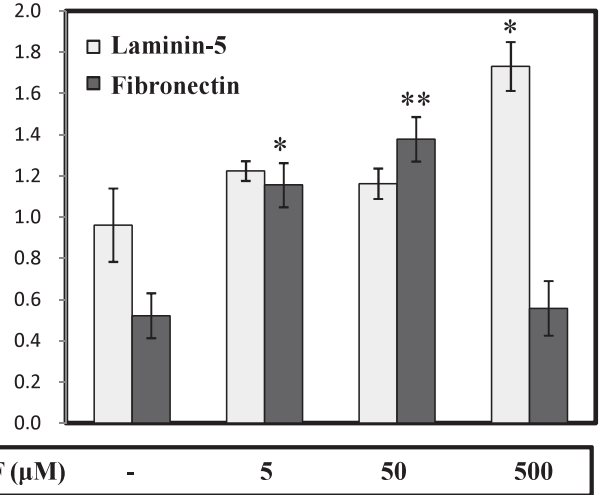

Fig. $4 \mathrm{NaF}$ increased fibronectin and laminin expression in epithelial cells. Fibronectin mRNA was up-regulated in $5 \mu \mathrm{M}$ and $50 \mu \mathrm{M}$ NaF-treated cells compared with control, whereas laminin mRNA was increased only in $500 \mu \mathrm{M} \mathrm{NaF-}$ treated cells. Relative mRNA levels were calculated as the ratio to that of $\beta$-actin, and each bar represents the mean \pm standard deviation for at least three independent experiments.

matrix assembly, such as fibronectin and laminin-5, leading to motility in epithelial cells. Fibronectin is considered to be a molecular switch that regulates matrix assembly, cell proliferation and gene ex- pression. Our real-time PCR analysis demonstrated that low-concentration $\mathrm{NaF}$ up-regulated fibronectin mRNA expression in the fluoride-treated cells compared with controls, suggesting that low-concentration $\mathrm{NaF}$ can have a targeted effect on fibronectin expression, rather than a general effect on protein synthesis. $\mathrm{NaF}$ at $1 \mathrm{ppm}$ stimulated proliferation, alkaline phosphatase activity and collagen synthesis in dental pulp cells (23). Bone is also affected by fluoride and a variety of cellular mechanisms have been proposed to explain increased bone formation during fluoride $(<2 \mathrm{ppm})$ treatment, which involves the MAPK mitogenic pathway $(8,21)$. There is currently little information about matrix assembly in epithelial cells during fluoride treatment. Our data revealed that $\mathrm{NaF}$ at low concentration invariably increases fibronectin in epithelial cells.

Human gingival epithelial cell expresses several laminin-binding integrin receptors $(15-17,20)$. During the healing of mucosal wounds in vivo, oral keratinocytes first secrete laminin-5 into their extracellular matrix, and start to deposit matrix-bound laminin $\alpha 5$ chain only after they have stopped migrating $(3,12)$. Less data are presently available on the expression and functions of laminin in cultured 
epithelial cells. Our present results, supported by previous findings, suggest that cultured human epithelial cells exposed to NaF produce laminin-5. In wound healing and many pathologic conditions, keratinocytes are activated to become migratory and hyper-proliferative cells that produce and secrete extracellular matrix components and signaling polypeptides. At the tooth-epithelium interface, epithelial cells deposit only laminin-5 into their extracellular matrix $(10,11)$, and our present in vitro findings show that this is the case also in cell culture. The relationship of such findings to the in vitro expression of laminin in epithelium remains a subject of further studies.

We measured the extracellular fluoride concentration in cells exposed to $5-500 \mu \mathrm{M}$ fluoride for $24 \mathrm{~h}$, by using the ion-selective electrode method. We found a slight difference in the extracellular fluoride concentration between NaF-treated cells and control cells, and therefore assume that fluoride may affect cells by crossing the plasma membrane, or may interact with certain cell surface molecules to modulate its extracellular events. Our results demonstrated that $\mathrm{NaF}$ is incorporated into the epithelial cells, but it remains unclear whether the incorporation and excretion change during the process. Further studies are needed to identify the proteins involved in fluoride signaling and to determine the role of these molecules in fibronectin expression by epithelial cells.

In summary, our data suggest that low concentration $\mathrm{NaF}$ is able to induce cell motility, migration, invasion and matrix production in epithelial cells. Any effect of fluoride on intracellular signaling processes might also be expected to influence cells to a greater extent. Additional data are needed to analyze the mechanisms of this induction.

\section{Acknowledgements}

We would like to extend our profound condolences and sincere sympathy to Dr. Yusuke Takahashi's family in the loss of our colleague.

\section{REFERENCES}

1. Boivin G, Chavassieux P, Chapuy MC, Baud CA and Meunier PJ (1989) Skeletal fluorosis: histomorphometric analysis of bone changes and bone fluoride content in 29 patients. Bone 10, 89-99.

2. Burgener D, Bonjour JP and Caverzasio J (1995) Fluoride increases tyrosine kinase activity in osteoblast-like cells: regulatory role for the stimulation of cell proliferation and $\mathrm{Pi}$ transport across the plasma membrane. J Bone Miner Res 10, 164-171.
3. Dabelsteen E, Grøn B, Mandel U and Mackenzie I (1998) Altered expression of epithelial cell surface glycoconjugates and intermediate filaments at the margins of mucosal wounds. J Invest Dermatol 111, 592-597.

4. DenBesten PK (1999) Biological mechanisms of dental fluorosis relevant to the use of fluoride supplements. Commun Dent Oral Epid 27, 41-47.

5. Duckworth RM and Morgan SN (1991) Oral fluoride retention after use of fluoride dentifrices. Caries Res 25, 123-129.

6. Evans RW and Darvell BW (1995) Refining the estimate of the critical period for susceptibility to enamel fluorosis in human maxillary central incisors. J Public Health Dent 55, 238-249.

7. Evans RW and Stamm JW (1991) An epidemiologic estimate of the critical period during which human maxillary central incisors are most susceptible to fluorosis. J Public Health Dent 51, 251-259.

8. Farley JR, Wergedal JE and Baylink DJ (1983) Fluoride directly stimulates proliferation and alkaline phosphatase activity of bone-forming cells. Science 222, 330-332.

9. Fejerskov O, Ekstrand J and Burt BA (1996) Fluoride in Dentistry, 2nd ed. Munksgaard, Copenhagen.

10. Giannelli G, Falk-Marzillier J, Schiraldi O, Stetler-Stevenson WG and Quaranta V (1997) Induction of cell migration by matrix metalloprotease-2 cleavage of laminin-5. Science 277, 225-228.

11. Goldfinger LE, Stack MS and Jones JC (1998) Processing of laminin-5 and its functional consequences: role of plasmin and tissue-type plasminogen activator. J Cell Biol 141, 255265.

12. Häkkinen L, Uitto VJ and Larjava H (2000) Cell biology of gingival wound healing. Periodontol 2000 24, 127-152.

13. Hassell TM (1993) Tissues and cells of the periodontium. Periodontol 2000 3, 9-38.

14. Hillier S, Inskip H, Coggon D and Cooper C (1996) Water fluoridation and osteoporotic fracture. Commun Dent Health 13, 63-68.

15. Hormia M, Owaribe K and Virtanen I (2001) The dentoepithelial junction: cell adhesion by type I hemidesmosomes in the absence of a true basal lamina. J Periodontol 72, 788797.

16. Hormia M, Virtanen I and Quaranta V (1992) Immunolocalization of integrin $\alpha 6 \beta 4$ in mouse junctional epithelium suggests an anchoring function to both the internal and the external basal lamina. $J$ Dent Res 71, 1503-1508.

17. Hormia M, Ylänne J and Virtanen I (1990) Expression of integrins in human gingival. J Dent Res 69, 1817-1823.

18. Imai T, Niwa M and Ueda M (1983) The effects of fluoride on cell growth of two human cell lines and on DNA and protein synthesis in HeLa cells. Acta Pharmacol Toxicol 52, $8-11$.

19. Kubota K, Lee DH, Tsuchiya M, Young CS, Everett ET, Martinez-Mier EA, Snead ML, Nguyen L, Urano F and Bartlett JD (2005) Fluoride induces endoplasmic reticulum stress in ameloblasts responsible for dental enamel formation. J Biol Chem 280, 23194-23202.

20. Larjava H, Salo T, Haapasalmi K, Kramer RH and Heino J (1993) Expression of integrins and basement membrane components by wound keratinocytes. J Clin Invest 92, 14251435.

21. Lau KH and Baylink DJ (1998) Molecular mechanism of action of fluoride on bone cells. J Bone Miner Res 13, 1660 1667.

22. Li Y, Decker S, Yuan ZA, Denbesten PK, Aragon MA, 
Jordan-Sciutto K, Abrams WR, Huh J, McDonald C, Chen E, MacDougall M and Gibson CW (2005) Effects of sodium fluoride on the actin cytoskeleton of murine ameloblasts. Arch Oral Biol 50, 681-688.

23. Nakade O, Koyama H, Arai J, Ariji H, Takada J and Kaku T (1999) Stimulation by low concentrations of fluoride of the proliferation and alkaline phosphatase activity of human dental pulp cells in vitro. Arch Oral Biol 44, 89-92.

24. Oguro A, Koizumi N and Horii K (1982) Effect of fluoride ion on proliferation of Vero cell line cells: growth acceleration by sodium fluoride. Koku Eisei Gakkai Zasshi 31, 5562 .

25. Presland RB and Dale BA (2000) Epithelial structural proteins of the skin and oral cavity: function in health and disease. Crit Rev Oral Biol Med 11, 383-408.

26. Sato T, Yagori A and Niwa M (1987) Low sensitivity of cultured human young adult and adult gingival fibroblasts to fluoride I. Relation to doubling time. Pharmol Toxicol 61, 313-315.

27. Thaweboon S, Thaweboon B, Chunhabundit P and Suppuk- patana P (2003) Effect of fluoride on human dental pulp cells in vitro. Southeast Asian J Trop Med Public Health 34, 915918.

28. Thrane EV, Refsnes M, Thoresen GH, Låg M and Schwarze PE (2001) Fluoride-induced apoptosis in epithelial lung cells involves activation of MAP kinases p38 and possibly JNK. Toxicol Sci 61, 83-91.

29. Whitford GM (1996) The Metabolism and Toxicity of Fluoride, 2nd rev. ed., Karger, New York.

30. Yan Q, Zhang Y, Li W and DenBesten PK (2007) Micromolar fluoride alters ameloblast lineage cells in vitro. $J$ Dent Res 86, 336-340.

31. Zager RA and Iwata M (1997) Inorganic fluoride. Divergent effects on human proximal tubular cell viability. Am J Pathol 150, 735-745.

32. Zuckerbraun HL, Babich H, May R and Sinensky MC (1998) Triclosan: cytotoxicity, mode of action, and induction of apoptosis in human gingival cells in vitro. Eur J Oral Sci 106, 628-636. 
